\title{
Falling weight impact response of jute/methacrylated soybean oil bio-composites under low velocity impact loading
}

\author{
H. N. Dhakal ${ }^{* a}$, M. Skrifvars ${ }^{\mathrm{b}}$, K. Adekunle ${ }^{\mathrm{b}}$, Z. Y. Zhang ${ }^{\mathrm{a}}$ \\ ${ }^{a}$ Advanced Polymer and Composites (APC) Research Group \\ School of Engineering \\ University of Portsmouth, Anglesea Road, Anglesea Building, Portsmouth, Hampshire, PO1 3DJ, \\ U.K. \\ ${ }^{\mathrm{b}}$ University College Boras, Allegatan 1, S 50190 Boras, Sweden.
}

\begin{abstract}
In this study, impact performance of bio-composites fabricated from jute/methacrylated soybean oil (MSO) subjected to low-velocity impact loading is presented. The composite laminates were fabricated using compression moulding technique and their thickness and weave architectures effect on the impact response were investigated and the experimental observations are reported. From the results obtained, it was observed that fibre orientation and thickness variation have a significant influence on the impact resistance of jute/MSO composite material. The results show that the total absorbed energy and maximum peak load increase linearly with an increase in the thickness. Among the composite samples investigated where thickness comprised of: 1, 1.5, 2, 2.5 and $3 \mathrm{~mm}$, a composite reinforced with 46 yarns per $10 \mathrm{~cm}$ weft and 50 warp (W2-3 mm thick) is found to have highest resistance to impact damage compared to 32 and 15 yarn per $10 \mathrm{~cm}$ weft samples. This was attributed to the improved fibre/matrix interface as a result of surface treatment of jute fibres and the fibre architectures effect which create the cross-over points which act as stress distributors.
\end{abstract}

Keywords: A. Fibres; A. Polymer-matrix composites (PMCs); B. Strength; B. Delamination.

* Corresponding author Tel: + 44 (0) 239284 2582; fax: + 44 (0) 2392842351.

E-mail: hom.dhakal@port.ac.uk (H.N. Dhakal). 


\section{INTRODUCTION}

Natural fiber reinforced composites based on renewable polymer have been developed in recent years, showing significant potential for various engineering applications due to their several positive environmental attributes, low cost and higher specific strengths compared to their conventional counterparts. Concerns over the end-of-life of non-degradable materials have motivated research into materials which are bio-degradable, renewable and environmentally friendly. A growing environmental awareness across the world has aroused interest in research and development of environmentally friendly and sustainable materials [1$6]$.

One of the major drawbacks of the natural fiber reinforced composites is their low impact strength as compared to glass fiber reinforced thermoplastic and thermoset composites [7, 8]. Low velocity impact damage can take place in composites when the objects such as runway debris, hand tools fall down on composites. Low velocity impact damage causes delamination which can reduce the structural integrity of the composite materials significantly. An understanding the effect of damage due to low velocity impact is an important subject to be investigated in a natural fiber reinforced composites in order to ascertain the capability of the composites to withstand impact load during their service life $[9,10]$. However, the impact resistance of a composite material is always difficult to determine due to some other factors such as delamination at the interface, fiber breakage, matrix cracking and fiber pull out [11, 12].

Several authors have reported the low velocity impact response of glass and carbon fiber reinforced composites [13-16]. There are many reported works on the mechanical and thermal properties of natural fiber reinforced composites [17-20]. Similarly, low velocity impact 
damage response of natural fibre reinforced composite materials has been subject of many experimental and numerical investigations. Bledzki et al. [21] studied the falling weight impact damage of abaca fibre reinforced polypropylene (PP) composite and compared with jute and flax fibre PP composite. Benevolenski et al. [22] investigated the transverse perforation impact behavior of flax mat reinforced PP composites with addition discontinuous cellulose and discontinuous glass fibre mat. Santulli [23] characterized falling weight impact damage on flax/epoxy laminates. It is evident from this literature that the impact damage characteristics of natural fibre composites with synthetic matrices like PP, epoxy, and unsaturated polyester, has been well documented. Adekunle et al. [24, 25] studied the mechanical properties of bio-based composites using bio-degradable resin such as lyocell and soybean oil. However, not much has been reported on the low velocity impact response of natural fibre composites with bio-degradable matrices such as methacrylated soybean oil. In this study, we investigated the effect of laminate thickness and fibre weave architectures effect on the low-velocity impact response of jute fiber reinforced methacrylated soybean oil composite. These new types of bio-composites can be employed in automotive parts such as bumper which often subject to minor to fully penetration of materials in their service life. Woven and non-woven laminates with various stitch density and different thickness were subjected to impact damage up to penetration via drop-weight impact machine. Four different types of jute fibers (non-woven and woven jute fabrics) were used, with the thickness ranging from $1 \mathrm{~mm}$ to $3 \mathrm{~mm}$. The impact history curves generated are studied and analysed to understand the damage response behavior of the laminates.

\section{EXPERIMENTAL}

\subsection{Materials}


Methacrylated soybean oil (MSO) was used as matrix in the preparation of the bio-composites. The chemical structure of the MSO is shown in Figure 1. The matrix resin was synthesized according to a method published earlier by Adekunle et al. [25]. Four different types of jute fibre reinforcements were used in the preparation of the composites: $\mathrm{Bi}$ axial woven jute fabrics with surface weights of 240,300 , and $100 \mathrm{~g} / \mathrm{m}^{2}$ were all supplied by HP Johannesson Trading AB, Järnvägsgatan 1, Svalöv, Sweden (see Figure 2 and Table 1). Non-woven jute fiber was also supplied by HP Johannesson (Figure 2a). The free radical initiator, tert-butylperoxybenzoate was supplied by Aldrich Chemical Company, Wyoming, IL, USA.

\subsection{Resin Blending}

Methacrylated soybean oil (MSO) was used as a matrix in the composite preparation. Viscosity of MSO was reduced by heating in an oven at $80^{\circ} \mathrm{C}$ for 10 minutes. The MSO was then blended with thermal initiator for high temperature curing, $2 \mathrm{wt} \%$ tert-butyl peroxybenzoate was used as a free radical initiator by blending with MSO resin. The resin was modified by polymerizing the epoxidized soybean oil with methacrylic acid.

\subsection{Composite preparations}

\subsubsection{Fibre surface treatment}

The jute fibers were washed with $4 \%$ sodium hydroxide solution for 1 hour and dried overnight; they were post-treated by heating at $105^{\circ} \mathrm{C}$ for 1 hour. As the natural fibers bear hydroxyl groups from cellulose and lignin, they are amenable to modification. The hydroxyl groups may be involved in the hydrogen bonding in the cellulose molecules, thereby reducing the activity towards the matrix. Chemical modifications may activate these groups or introduce new moieties that can effectively interlock with the matrix. 
Composite laminates were made by stacking sheets of fiber mats as a preform and resin impregnation was done by hand-spraying. The prepreg was then inserted in a mould and compression moulded at $160^{\circ} \mathrm{C}$ for 5 min using a pressure of 40 bar to get an approximate thickness of $1 \mathrm{~mm}-3 \mathrm{~mm}$ for the composites. There was no specific fibre direction in the case of the jute woven fabrics because they are bi-axially woven. The hot press was supplied by Rondol Technology Ltd., Staffordshire, UK. The fiber/resin ratio was about 60:40 wt. \% in all cases. Composites reinforced with fabric surface weights $240 \mathrm{~g} / \mathrm{m}^{2}, 300 \mathrm{~g} / \mathrm{m}^{2}$ and $100 \mathrm{~g} / \mathrm{m}^{2}$ were denoted W1, W2 and W3 respectively. For composite W1, W2 and W3, 14, 10 aand 24 plies were used. The Tg of the composites laminates was $130 \mathrm{oC}$.

A total of 25 different laminates were made (5 laminates for each fiber of type, having different thicknesses such as $1 \mathrm{~mm}, 1.5 \mathrm{~mm}, 2 \mathrm{~mm}, 2.5 \mathrm{~mm}$ and $3 \mathrm{~mm}$ ). 5 specimens with a dimension of $70 \mathrm{~mm} \times 70 \mathrm{~mm}$ were cut from each laminate.

\subsection{Drop weight impact test}

The low-velocity impact tests were performed at room temperature on Zwick/Roell HIT230F drop weight test machine with an impactor of constant mass $23.11 \mathrm{~kg}$ from an initial height of $110 \mathrm{~mm}$ with a hemispherical steel tup diameter of $19.8 \mathrm{~mm}$ as depicted in Figure 3. The drop height was adjusted to generate 25 Joules of incident impact energy sufficiently enough to perforate the square specimens of side length $70 \mathrm{~mm}$ with thickness varying from $1 \mathrm{~mm}$ to $3 \mathrm{~mm}$. A catcher mechanism was activated to avoid the multiple damages on the specimens. The impact test history, including impact force, impact time and energy absorbed were obtained by the instrumented tip.

\section{Results and discussion}

\subsection{Influence of thickness and fibre architecture on damage and energy dissipation}


The impact response of jute/MSO bio-composites were evaluated with respect to the data pertaining to the resulting impact damage patterns, impact load and the energy absorbed. All average results from impact testing for different samples are presented in Table 2. The impact response of jute/MSO bio-composites in terms of force versus time and energy versus time are shown in Figures 4-5.

Figure 4 (a-c) shows typical force-time traces following impact tests on four different laminates with thicknesses from $1 \mathrm{~mm}$ to $3 \mathrm{~mm}$. The value of maximum force as a function of impact time (Figure 4 and Table 2) show force-time curves were linear up to the critical force. The peak force for $3 \mathrm{~mm}$ thick non-woven sample (Fig. 4 a) recorded was 1682 N. The peak force for woven W1, W2 and W3 for $3 \mathrm{~mm}$ thick specimens (Fig. 4 (b-d) was approximately 2704, 3283 and $1700 \mathrm{~N}$, respectively. The peak force for woven W2 sample compared to non-woven sample is approximately $95 \%$ higher. This trend for highest peak force for W2 samples compared to other samples was because of the reinforcement in this composite was denser as a result of short distance between two adjacent roving wefts. In addition, the differences in peak forces are likely to be due to variation in the elastic property of the bio-composite laminates. The load versus time curves for jute/MSO bio-composites reveals that the peak impact force increases with increasing aerial weight as well as fibre geometry.

The influence of thickness on the energy absorption for various samples is shown in Figure 5 (a-d). The corresponding energy plots from the experimental results show a strong influence of sample thickness on the amount of absorbed energy. It can be seen from the figure that the absorbed energy increases in a linear manner with increasing sample thickness. The $1 \mathrm{~mm}$ thick samples have the lowest absorbed energy for all categories of the samples. This is attributed to lower stiffness of the sample at lower thickness level as the fibre 
content at lower thickness is less than the higher thickness samples. The thicker the composite laminate, the smaller the damage area as a result of lesser displacement. Similar trend of thickness effect on the impact damage characteristics was reported for glass fibre composites elsewhere [24].

\subsection{Damage characteristics}

The failure modes in composites are an important factor in damage analysis as they provide information not only on impact event but also on the residual strength of impacted specimens $[25,26]$. The failure during the impact event for different specimens is deciphered by the load time curves presented in Figure 6. As it can be seen from the averaged representative values from $3 \mathrm{~mm}$ thick specimen curves that the critical force, the incipient damage point where sudden load drops $\left(\mathrm{P}_{\text {critical }}\right)$, is recorded $1450 \mathrm{~N}$ for non-woven jute sample. Whereas, the critical force for woven samples, W1, W2 and W3 are recorded as 1937, 2032 and $1360 \mathrm{~N}$, respectively. The difference between the critical force and the maximum for non-woven sample is approximately $16 \%$ whereas for woven specimens, for example W1 and W2, the difference between critical force and the maximum force is approximately 39 and $36 \%$, respectively. This big difference between the critical force and the maximum force is an indication of longer propagation phase, hence specimens showing better impact resistance.

The incipient damage point, also referred as onset of delamination, is a consequence of internal delamination or fibre matrix failure in the composites. This delamination process is accompanied by a rapid reduction of the force due to the reduction in the stiffness of the composite laminates. A reloading phase of the specimens to the maximum point, $\mathrm{P}_{\max }$ can be seen occurred for all specimens. It is clear that higher impact force generates higher impact energy for all tested specimens. At lower impact force, hence at 
lower thickness specimens, all the samples showed lower impact energy. At higher force levels, all specimens showed greater impact energy.

The instrumented falling weight impact testing involves small time scales. The time taken for the damage initiation and propagation through the entire specimen to the point of total collapse is approximately 7-9 ms for non-woven jute and the longest time taken for W2 $3 \mathrm{~mm}$ sample is $19 \mathrm{~ms}$ (Table 2). This indicates that the time duration for the impact event is strongly influenced by the fibre architecture, areal weight and the thickness of the composite laminates.

Impact damage in fibre reinforced composites involves four major failure modes; namely matrix cracking, delamination, fibre breakage and penetration of the impacted surface [14]. The damage states of jute fibre reinforced/MSO composite specimens shown in load/time traces in Figure 6 can be explained further as follows. The load/time trace of $3 \mathrm{~mm}$ thick non-woven and woven specimens have been considered as a representative curve for this illustration. At stage 1 (P1), there is no damage occuring. As the load increases, matrix cracking occurs at stage $2(\mathrm{P} 2)$. This point can be considered as a boundary between elastic and plastic phase. At this point, as the load further increased, the size and extent of the matrix cracking may progress such that interfacial debonding occurs at stage 3 (P3). Because of the serious impact damage and the plastic deformation in the laminate, no further damage development is expected at this stage. This, in turn, leads to delamination, then fibre breakage, and finally, perforation/penetration of the impacted specimen takes place at stage $4(\mathrm{P} 4)$. Because of the serious impact damage and the plastic deformation in the laminate, no further damage development is expected at this stage.

The damage types corresponding to states $1,2,3$, and 4, are highlighted in Figure 6. It is important to note that the damage size and the damage type observed in the 
impact event in this study are influenced by number of factors such as fibre volume fractions, matrix property and the orientation of fibres.

\subsection{Comparison with impact response of different bio-composites}

In an impact event, peak force and impact test time are important parameters influencing impact damage characteristics. The impact force versus time traces for different specimens as presented in Figure 4 show that there is a linear relationship between the peak force and the composite thickness. It can also be seen that the duration of impact time increases as the specimen thickness increases for all type of specimens. Amongst the studied samples, woven samples, W1 and W2 showed highest peak load compared to non-woven specimen. This is explained by the fact that woven laminates possess' greater toughness with respect to the initiation of interlaminar cracks and as a result these composites offer better resistance to impact damage through the cross-over points, which acts as stress distributors.

Referring back to the stages of damage at various forces for different specimens in Fig. 6, $\mathrm{P}_{\max }$ is related to the delamination size of the specimens. Non-woven samples have the largest delamination area, thus indirectly having lowest $\mathrm{P}_{\max }$. The presence of larger delamination area implies that the stiffness of the impacted non-woven plate is much lower than that of woven specimens [27]. Since the influence of fibre architecture has greater influence on the delamination size; which is more apparent at higher thickness levels, there is likewise greater difference in Pmax among the specimens. Similarly, Pcritical follows the similar pattern; hence increase Pcritical value with the increase in thickness (Figure 6). The reason for higher impact resistance for $\mathrm{W} 2$ is attributed as a result of higher fibre volume fraction (areal weight).

The average energy absorption curves for impacted samples indicate that woven composites show higher energy absorption than non-woven samples. The average energy 
absorption for non-woven sample with $3 \mathrm{~mm}$ thickness found to approximately $12 \mathrm{~J}$, which is about $33 \%$ lower than the energy absorption (16 J) by woven (W1) sample with similar thickness. Amongst the woven samples, the average energy absorption by W3 sample with 3 $\mathrm{mm}$ thickness was found to $14 \mathrm{~J}$ which is about $17 \%$ higher than the non-woven sample energy absorption (12 J) with the similar thickness. The average energy absorption for $3 \mathrm{~mm}$ thick woven W2 sample was recorded approximately as being $16 \mathrm{~J}$ which is approximately $33 \%$ higher than non-woven sample and approximately 14\% higher than the W3 sample with similar thickness. The poor impact performance of non-woven sample is attributed to fabric weave architectures and the lower fibre aerial weight. It is evident from the above results that the type of fibre, fibre weave architectures and the fibre orientation significantly affects the impact behaviour of composites. Compared to non-woven, woven laminates possess large toughness as these laminates offer better resistance to impact damage through the cross-over points, which act as stress distributors.

\subsection{Characteristics of post impact surface damages of composite plates}

Post impact damage characteristics of representative samples of $3 \mathrm{~mm}$ thickness are shown in Figures 7 and 8. It is clear from the visual inspection from these post impacted front and rear faces of non-woven sample that as the thickness and fibre areal weight increase, the presence of a perfectly circular area at the front face of the sample and the presence of spalling (material loss) at the back face is evidence. The damage area on the front face of laminate results from the direct contact of the impactor and the damage area on the back face are due to the longer damage propagation time taken for the samples with higher areal weight. The Figures 7 and 8 further show damage observed on the front and rear faces of woven jute/MSO (W1) specimen. As it can be seen clearly from the figures, the damage area on the front face is not perfect circular and the damaged area is larger compared to non-woven specimens. The clear circular hole is more evident as the thickness and fibre areal weight is 
increased. The front and rear faces of impacted specimen for woven jute/MSO (W2) is shown in Figures 7-8. It is clear from the figure that the damage area on the front face is not perfect. The clear circular hole is more evident as the thickness is increased. Figure 7 presents the damage patterns for woven jute W3 specimens. The impact damage on the front face is close to the size of the impactor, but on the rear face, the delamination and crack seems growing outwards.

It is clear from the figures 7-8 that all the samples impacted suffered fully penetration damage. This implies that thin specimens for all categories samples had more surface damage than the thick specimens. Similarly, the variation on the impact damage characteristics observed for different specimens are attributed to the fibre architectures, mainly the distance between the adjacent roving wefts and warps; which contributed to the surface weight of the fabric [28]

\subsection{Industrial implications of the findings from this study}

Automotive industry is leading the way as far as using natural fibre composites and bio-composites are concerned. The recycling and recovery of end-of-life vehicles, which involves recovery targets of $85 \%$, are driving the auto industries to adopt light weight and biodegradable materials to meet these recovery targets [29]. Most of the cars produced in Europe currently use an average of 5-10 Kg natural fibres in various non-structural parts such as door trim panels, parcel shelves and other interior parts [30]. Parts made by using conventional reinforcements such as glass and carbon fibre are expensive and heavy as well as poor in toughness and acoustic properties. The composites and bio-composites reinforced using fibres such as jute into resin like Methacrylated soybean oil (MSO) not only provide weight saving, but they are green and provide enhanced toughness and specific stiffness with superior acoustic property at lower cost compared to their synthetic counterparts. The results obtained 
from this study are encouraging enough to warrant further development of sustainable green composites based on renewable resources such as jute/MSO bio-composite materials.

\section{Conclusions}

Bio-composites are gradually emerging as a viable alternative to conventional fibre reinforced composites in several industrial applications. In this study, methacrylated soybean oil (MSO) bio-composite laminates reinforced from non-woven and woven jute fibre with laminate thicknesses $1,1.5,2,2.5$ and $3 \mathrm{~mm}$ are successfully fabricated and their thickness and weave architectures effect on the low-velocity impact damage characteristics were investigated. Important parameters such as peak force and absorbed impact energy show that impact resistance behavior of biocomposites studied was significantly influenced by the type of fibre, fibre weave architectures and the fabric areal weight. It has been further revealed that the onset of damage force, Pcritical, changes with variation in the thicknesses of the jute/MSO laminates. Compared to non-woven, woven laminates possess better toughness properties as these laminates offer better resistance to impact damage through the cross-over points which act as stress distributors. At the onset of delamination, there was deviation in the impact loadtime history for all samples studied and the difference between critical force and maximum peak force was greater for woven specimens compared to non-woven; hence indicating greater propagation phase by woven specimens. The damage initiation force and the propagation phase were found greater for woven composites samples compared to non-woven samples. Among the bio-composites studied, woven W2 sample displays the greatest impact resistance due to its higher areal weight and higher yarn per $10 \mathrm{~cm}$ compared to other specimens. 


\section{References}

[1] Bolton J. The Potential of Plant Fibres as Crops for Industrial Use. Outlook on Agriculture 1995; 24: 85-9.

[2] Bledzki AK, Gassan J. Composites reinforced with cellulose base fibres. Prog Polym Sci 1999, 24: 221-74.

[3] Adekunle K, Akesson D, Skrifvars M. Mechanical and viscoelastic properties of soybean oil thermoset reinforced with jute fabrics and carded lyocell fiber. Journal of Applied Polymer Science 2011; 122(5): 2855-2863.

[4] Dhakal HN, Zhang ZY, Richardson MOW. Effect of water absorption on the mechanical properties of hemp fibre reinforced unsaturated polyester composites. Compos Sci Technol. 2007; 67:1674-1683.

[5] Dhakal, H.N., Zhang, Z. Y. and Richardson, M. O. W. Creep behaviour of hemp fibre reinforced unsaturated polyester composites. Journal of Biobased Materials and Bioenergy 2009; 3:232-237.

[6] Faruk, O, Bledzki AK, Fink, HP, Sain, M. Biocomposites reinforced with natural fibres:2000-2010. Progress in Polymer Science 2012, 37:1552-1596.

[7] Bledzki AK, Gassan J, Zhang W. Impact properties of natural fibre reinforced epoxy foams. J Cell Plast 1999; 35: 550-62.

[8] Dhakal HN, Zhang ZY, Richardson MOW, Errajhi OAZ. The low velocity impact response of non-woven hemp fibre reinforced unsaturated polyester composites. Compos Struct. 2007; 81: $559-67$.

[9] De Rosa, Igor M. Dhakal HN. Santulli C, Sarasini F. Zhang ZY. Post-Impact Static and Cyclic Flexural Characterisation of Hemp Fibre Reinforced Laminates. Composites Part B 2012; 43:1382-1396.

[10] Dhakal HN, Zhang ZY. Bennett N. Reis PNB. Low-velocity impact response of nonwoven hemp fibre reinforced unsaturated polyester composites: Influence of impactor geometry and impact velocity. Composite Structures, 2012; 94: 2756-2763

[11] Santulli C. and Caruso AP. A comparative study on falling weight impact properties of jute/epoxy and hemp/epoxy laminates Malaysian Polymer Journal, 2009; 4:19-29. 
[12] Wang S, Chung DDL, Chung JH. Impact damage of carbon fibre polymer-matrix composites, studied by electrical resistance measurement. Compos Part A-Appl S 2005; 36: 1707-15.

[13] Wisheart M, Richardson MOW. Low velocity response of a complex geometry pultruded Glass/Polyester Composite. J Mater Sci 1999; 34: 1107-16.

[14] Richardson MOW, Wisheart MJ. Review of the low velocity impact properties of composites materials. Compos Part A-Appl S 1996; 27: 1123-31.

[15] Cantwell WJ, Morton J. The impact resistance of composite materials; a review. Composites 1991; 22: 347-62.

[16] Mitrevski T, Marshall IH, Thomson R. The influence of impactor shape on the damage to composites laminates. Compos Struct 2006; 76: 116-22.

[17] Jacob M, Thomas S, Varughese KT. Mechanical properties of sisal/oil palm hybrid fibre reinforced natural rubber composites. Compos Sci Technol 2004; 64: 955-65.

[18] Gassan J, Cutowski VS. Effect of corona discharge and UV treatment on the properties of jute-fiber epoxy composites. Compos Sci Technol 2000; 60: 2857-63.

[19] Sombatsompop N, Chaochanchaikul K. Effect of moisture content on mechanical properties, thermal and structural stability and extrudate texture of poly(vinyl chloride)/wood sawdust composites. Polym Int. 2004; 53: 1210-18.

[20] Dhakal HN, Zhang ZY, Bennett N. Influence of fibre treatment and glass fibre hybridisation on thermal degradation and surface energy characteristics of hemp/unsaturated polyester composites, Composite Part B 2012;43:2757-2761

[21] Bledzki AK, Mamum AA, Faruk, O. Abca fibre reinforced PP composites and comparison with jute and flax fibre PP composites. eXpress Polymer Letter 2007; 1:755-762.

[22] Benevolenski OI, Karger-Kocsis J, Mieck KP, Reubmann T. Instrumented performation impact response of polypropylene composites with hybrid reinfrocement flax/glass and flax/cellulose fibres, Journal of Thermoplastic Composite Materials 2000; 13:

[23] Santulli C. Falling weight impact damage characterisation on flax/epoxy laminates. International Journal of Materials and Product Technology; 36:221-228. 
[24] Adekunle K, Cho SW, Patzeltc C. Impact and flexural properties of flax fabrics and Lyocell fiber-reinforced bio-based thermoset. Journal of Reinforced Plastics and Composites, 2011. 30(8): p. 685-697

[25] Adekunle K, Åkesson D, Skrifvars M. Biobased composites prepared by compression molding with a novel thermoset resin from soybean oil and a natural-fiber reinforcement. Journal of Applied Polymer Science 2010; 116: 1759-1765.

[26] Whittingham B, Marshall IH, Mitrevski T, Jones R. The response of composite structures with pre-stress subject to low velocity impact damage. Compos Struct. 2004; 66: 685-98.

[27] De Rosa IM, Santulli C, Sarasini F, Valente M, Post-impact damage characterization of hybrid configurations of jute/glass polyester laminates using acoustic emission and IR thermography, Composites Science and Technology 69 (7-8), 2009, 1142-1150.

[28] Cantwell WJ. Geometrical Effects in the Low Velocity Impact Response of GFRP, Compos Sci Technol. 2007; 67: 1900-08

[29] Mcwilliams A. Advanced materials, light weight materials in transportation, report, 2007, Report code: AVM056A.

[30] Bhanawat PD, Patil VM. Textile fibre composites and their applications. International Journal of Science and Innovations and Discoveries. 2012; 2:50-61. 


\section{Table captions}

Table 1: Characterization of jute fabric reinforcements

Table 2: Average impact test results for various samples

Table 1: Characterization of jute fabric reinforcements

\begin{tabular}{ccccc}
\hline Fibers & $\begin{array}{c}\text { Yarn per 10cm } \\
\text { (weft) }\end{array}$ & $\begin{array}{c}\text { Yarn per 10cm } \\
\text { (warp) }\end{array}$ & $\begin{array}{c}\text { Twist } \\
\text { (turns per inch) }\end{array}$ & Surface weight $\left(\mathrm{g} / \mathrm{m}^{2}\right)$ \\
\hline W1 & 32 & 40 & $4-5$ & 240 \\
\hline W2 & 46 & 50 & $4-5$ & 300 \\
\hline W3 & 15 & 17.5 & $4-5$ & 100 \\
\hline
\end{tabular}

Table 2: Average impact test results for various samples

\begin{tabular}{|c|c|c|c|c|c|c|c|c|c|c|c|c|c|c|c|}
\hline \multirow[t]{3}{*}{ Samples } & \multirow{2}{*}{\multicolumn{5}{|c|}{$\begin{array}{l}\text { Test duration }(\mathrm{ms}) \\
\text { Thickness }(1-3 \mathrm{~mm})\end{array}$}} & \multicolumn{5}{|c|}{ Peak load (N) } & \multicolumn{5}{|c|}{ Total energy $(\mathrm{J})$} \\
\hline & & & & & & \multicolumn{5}{|c|}{ Thickness (1-3 mm) } & \multicolumn{5}{|c|}{ Thickness (1-3 mm) } \\
\hline & 1 & 1.5 & 2 & 2.5 & 3 & 1 & 1.5 & 2 & 2.5 & 3 & 1 & 1.5 & 2 & 2.5 & 3 \\
\hline NWJ & 7 & 8 & 8 & 8 & 9 & 265 & 655 & 502 & 1344 & 1682 & 0.93 & 3.93 & 5.70 & 11.94 & 11.63 \\
\hline WJ (W1) & 7 & 9 & 10 & 10 & 10 & 388 & 731 & 1628 & 1748 & 2704 & 1.90 & 4.99 & 8.83 & 9.82 & 15.74 \\
\hline $\mathrm{WJ}(\mathrm{W} 2)$ & 5 & 6 & 8 & 12 & 19 & 330 & 612 & 947 & 1822 & 3283 & 1.19 & 2.55 & 2.93 & 9.83 & 16.27 \\
\hline WJ (W3) & 4 & 9 & 10 & 10 & 11 & 300 & 576 & 764 & 1365 & 1700 & 1.14 & 3.86 & 6.10 & 7.19 & 13.83 \\
\hline
\end{tabular}

